\title{
Basic science, translational research and surgery: an unresolved controversy
}

\author{
Francesco Giovinazzo $\cdot$ Sara Zanini $\cdot$ \\ Claudio Bassi
}

Received: 22 October 2012/Accepted: 5 November 2012/Published online: 22 November 2012

(C) Springer-Verlag Italia 2012

\section{Dear Sir,}

During the centuries, surgeons have contributed to the advance of the medicine improving the surgical outcomes in daily clinical practice and participating to the progress of the basic research science. In 1909, Dr. Teododor Koker was the first surgeon to win the Nobel Prize, and in 1990, Dr. Joseph Murray was the seventh and the last surgeon to reach the award [1]. Therefore, together with other academic figures traditionally more oriented towards basic science, the surgeon always had an irreplaceable role in the development of medical science from both points of view, practical and intellectual through a process of gradual awareness and participation in the development of the research projects [2].

In recent years, the explosion of molecular biology has shown that this discipline, often confined to basic research, occupies an important place in surgical research. The impact on clinical practice varies from the analysis of molecular biomarkers and genetic risk of cancer to the application of transgenic technologies in xenografts [3].

Playing in this scenario, the question about the role of the surgeon in translational research and basic science becomes every day more urgent to plane the future of the Academic Departments of Surgery, whose central mission is to produce new knowledge and validate the laboratory

F. Giovinazzo $\cdot$ S. Zanini · C. Bassi

Laboratory of Translational Surgery, Department of Surgery, University Laboratories of Medical Research (LURM),

G.B. Rossi Hospital, University of Verona,

Piazzale L.A. Scuro 10, 37134 Verona, Italy

C. Bassi $(\bowtie)$

Department of Surgery, Pancreas Center, University of Verona, School of Medicine, Piazzale L.A. Scuro 10, 37134 Verona, Italy e-mail: claudio.bassi@univr.it results in the clinical practice. Therefore, looking at this radical change of perspective, the academic surgical community is called to answer several questions. Is it sufficient for us to be a good surgeon focused only on the quality of care or worth equipping and accepting the challenge, playing a game in an integrated research system? Could the strong practical experience of the surgical disciplines improve the theoretical approaches of basic sciences? Could the privileged relationship with the patient help to humanize the research interpreting the deepest need of the human being? Could the surgeon contribute to drive the results of basic science towards clinical applications in the era of genomics and proteomics? All these questions converge towards the conclusions that in the future academic surgeons will have a key role in the development of translational research program, and the surgical community needs to re-address our own vision of the research [4].

Conflict of interest The authors declare that there is no conflict of interest that could be perceived as prejudicing the impartiality of the research reported.

\section{References}

1. Cosimi AB (2006) Surgeons and the Nobel Prize. Arch Surg 141:340-348

2. Hudson TJ, Anderson W, Artez A et al (2010) International network of cancer genome projects. Nature 464:993-998

3. Stojadinovic A, Ahuja N, Nazarian SM et al (2010) Translational research in surgical disease. Arch Surg 145:187-196

4. Ahmed K, Ibrahim A, Anderson O et al (2011) Development of a surgical educational research program-fundamental principles and challenges. J Surg Res 167:298-305 